\title{
Subsets of regulatory $T$ cells and their roles in allergy
}

\author{
Huiyun Zhang ${ }^{1,2+}$, Hui Kong ${ }^{3+}$, Xiaoning Zeng ${ }^{3}$, Lianyi Guo ${ }^{1}$, Xiaoyun Sun ${ }^{1}$ and Shaoheng He ${ }^{1 *}$
}

\begin{abstract}
In recent years, it is recognized that acquired immunity is controlled by regulatory T cell (Treg). Since fundamental pathophysiological changes of allergy are mainly caused by hyperresponsiveness of immune system to allergens that acquires after birth, Tregs likely play key roles in the pathogenesis of allergy, particularly during the sensitization phase. However, accumulated information indicate that there are several distinctive subtypes of Tregs in man, and each of them seems to play different role in controlling immune system, which complicates the involvement of Tregs in allergy. The aim of the present study is to attempt to classify subtypes of Tregs and summarize their roles in allergy. Tregs should include natural Tregs (nTreg) including inducible costimulator (ICOS)(+) Tregs, inducible/ adaptive Tregs (iTreg), interleukin (IL)-10-producing type 1 Tregs (Tr1 cells), CD8(+) Tregs and IL-17-producing Tregs. These cells share some common features including expression of Foxp3 (except for Tr1 cells), and secretion of inhibitory cytokine IL-10 and/or TGF- $\beta$. Furthermore, it is noticeable that Tregs likely contribute to allergic disorders such as dermatitis and airway inflammation, and play a crucial role in the treatment of allergy through their actions on suppression of effector T cells and inhibition of activation of mast cells and basophils. Modulation of functions of Tregs may provide a novel strategy to prevent and treat allergic diseases.
\end{abstract}

Keywords: Regulatory T cell, Allergy, IL-10, TGF- $\beta$, Mast cell

\section{Introduction}

Allergic diseases are major diseases involving approximately $22 \%$ world population [1]. The diseases include allergic rhinitis, allergic asthma, allergic dermatitis, allergic conjunctitis, anaphylaxis, food or drug allergic reactions etc. It has long been accepted that allergic inflammation is the fundamental pathological changes of allergy, and type I hypersensitivity of immune system is the basic mechanism of allergic inflammation [2]. There are two phases in the basic process of IgE mediated allergic inflammation, the sensitization phase and effection phase.

It has long been recognized that lymphocytes guide (if not dictate) the sensitization of allergy by directing differentiation of uncommitted (naive) CD4 $(+) \mathrm{T}$ helper (Th) cells towards Th1, Th2, Th17 and Treg phenotypes. For example, the presence of IL-12 in the local

\footnotetext{
* Correspondence: shoahenghe@hotmail.com

${ }^{\dagger}$ Equal contributors

'Allergy and Clinical Immunology Research Centre, the First Affiliated Hospital of Liaoning Medical University, No. 2, Section 5, Renmin Street, Guta District, Jinzhou, Liaoning 121001, People's Republic of China

Full list of author information is available at the end of the article
}

milieu skews towards Th1 [expression of $\mathrm{T}$ box expressed in T cells (T-bet)], IL-4 towards Th2 (expression of GATA-3), transforming growth factor (TGF)- $\beta$ towards Treg [expression of forkhead box P3 (Foxp3)] and IL-6 and TGF- $\beta$ towards Th17 (expression of RORgammat) in murine CD4(+) $\mathrm{T}$ cells. It has also been demonstrated that the skewing of murine Th towards Th17 and Treg is mutually exclusive, notably the presence of IL- 6 may result in a shift from a regulatory phenotype towards a Th17 [3]. It is clear that individuals with defective or suboptimal Foxp3 expression due to mutations in Foxp3 gene or in genes that promote Foxp3 expression such as STAT5b are susceptible to allergic diseases [4]. Very recently, it has been noticed that insufficient Treg and Th1 cells may be associated with the allergic inflammation that may be attributed to the Th2 immune response in patients suffering from allergic rhinitis who are sensitive to olive pollen [5].

In recent years, Tregs have been emerging as key focus in the sensitization phase of the pathogenesis of allergy. It is recognized that acquired immunity is controlled by Tregs that suppress responses of effector $\mathrm{T}$ cells. Tregs 
can be classified into nTregs [6] including inducible costimulator $(\mathrm{ICOS})(+)$ Tregs [7], iTregs [4], Tr1 cells [8], CD8(+) Tregs [9] and IL-17-producing Tregs [10]. These cells share some common features including expression of Foxp3 (except for Tr1 cells), and secretion of inhibitory cytokine IL-10 and/or TGF- $\beta$ (Table 1 ).

\section{Subsets of Tregs}

At least 5 subsets of Tregs are identified so far. They are derived from naive $\mathrm{T}$ cells under different conditions, and play a crucial role in controlling allergic diseases.

\section{nTregs}

The CD4(+)CD25(+)Foxp3(+) cells, which secret IL-10 and TGF- $\beta$, and represent one of the largest subsets of Treg. In mice, the cytokines associated with the Treg subset include both soluble and cell membrane-bound TGF- $\beta$ and IL-10. Both contact-dependent mechanisms involving membrane-bound TGF- $\beta$ to block T cell proliferation and contact-independent mechanisms involving soluble TGF- $\beta$ and IL-10 have been invoked to describe the function of these Tregs [11]. These cells originate from thymus in response to self-antigens [9]. Their roles in allergen-specific immune reactions include suppression of dendritic cells that support the generation of effector T cells; inhibition of functions and migration of effector Th1, Th2, and Th17 cells; elimination of production of allergen-specific IgE and induction of IgG4 secretion; suppression of mast cells, basophils, and eosinophils; interaction with resident tissue cells and participation of tissue remodeling [12].
Very recently, CD4(+)CD25(+)CD127(lo/-) Foxp3(+) Tregs are detected in the neonatal thymus. These cells suppress the proliferative response to allogeneic stimulation of CD4(+)CD25(-) T cells dose dependently. It is also found that Treg turnover and suppressive function increases with age and paralleled the increase in global thymic Foxp3 mRNA expression in nonatopic children, whereas Treg cell maturation is significantly delayed in atopic children, implicating that the immune dysregulation in atopic children might predispose to allergic disease [13]. It has also been reported inverse correlation between expression of FoxP3 and CD127 in CD4 + CD25+ T cells, which suggests that cell surface expression of CD127 can be used as a flexible alternative to the transcription factor FoxP3 for identifying and isolating human Tregs for functional analysis [14].

ICOS(+) Tregs are distinguishable from all other Foxp3 (+) Tregs by the expression of IL-10, IL-17, and interferon (IFN)-gamma. ICOS(+) Tregs derived from the expansion of nTregs rather than generation of adaptive Tregs in response to their cognate antigen. CD25(+)Foxp3(+)ICOS(+) phenotype expresses high levels of ICOS in vivo following sensitization with 2,4-dinitro-fluorobenzene, and specifically suppresses hapten-reactive CD8(+) T cells with superior suppressive activity [15].

\section{iTregs}

In contrast to nTregs, iTregs are peripherally induced Tregs. Naive CD4+ T cells in the periphery are induced to express Foxp3 in response to foreign antigens [9] and these cells have suppressive function similar to nTregs [16].

Table 1 Characteristics of subsets of regulatory $\mathrm{T}$ cell (Treg)

\begin{tabular}{|c|c|c|c|c|}
\hline Subset & Specific marker & $\begin{array}{l}\text { Secretory } \\
\text { products }\end{array}$ & Actions & Location \\
\hline nTreg & CD4, CD25, Foxp3 & IL-10, TGF- $\beta$ & $\begin{array}{l}\text { Block T cell proliferation, suppression of DCs, } \\
\text { inhibition of effector Th1, Th2, and Th17 cells; } \\
\text { eliminate production of allergen-specific lgE, } \\
\text { induce IgG4 secretion; suppress mast cells, } \\
\text { basophils, and eosinophils; interact with } \\
\text { resident tissue cells and participate tissue } \\
\text { remodeling [12] }\end{array}$ & Thymus [9] \\
\hline ICOS(+) Treg & CD4, CD25, Foxp3, ICOS & $\begin{array}{l}\text { IL-10, IL-17, } \\
\text { IFN- } \gamma\end{array}$ & Suppress hapten-reactive CD8(+) T cells [15] & Generated from nTregs \\
\hline iTreg & CD4, Foxp3 & IL-10, TGF- $\beta$ & Similar to nTreg [16] & Periphery \\
\hline Tr1 & CD4, CD25 & $\mathrm{IL}-10$ & $\begin{array}{l}\text { Suppress effector Th cell migration and } \\
\text { functions [4]; suppress mast cells, basophils, } \\
\text { and eosinophils [8] }\end{array}$ & $\begin{array}{l}\text { Generated from non-Treg cell precursors } \\
\text { and home lungs and draining lymph } \\
\text { nodes [18] }\end{array}$ \\
\hline CD8(+)Treg & $\begin{array}{l}\text { CD8, Foxp3, CD25 } \\
\text { (not for tonsil origin), } \\
\text { CD28 }\end{array}$ & $\begin{array}{l}\text { IL-10, TNF-a, } \\
\text { IFN- } \gamma, G B\end{array}$ & $\begin{array}{l}\text { Block activation of naive or effector } T \text { cells; } \\
\text { suppress lgG/lgE antibody responses [9], IL-4 } \\
\text { expression and the proliferation of CD4(+) } \\
\text { T cells [19]. }\end{array}$ & $\begin{array}{l}\text { Generated from OT-1 CD8 cells [9]and } \\
\text { tonsils }\end{array}$ \\
\hline $\begin{array}{l}\text { IL-17-producing } \\
\text { Foxp3 (+) Treg }\end{array}$ & $\begin{array}{l}\text { CD4, Foxp3,CCR6, } \\
\text { RORGTF }\end{array}$ & $\mid \mathrm{L}-17$ & $\begin{array}{l}\text { Inhibit the proliferation of CD4(+) effector } \\
\text { T cells [10]. }\end{array}$ & $\begin{array}{l}\text { Differentiated from CD4(+)Foxp3(+)CCR6(-) } \\
\text { Tregs in peripheral blood and lymphoid } \\
\text { tissue [10] }\end{array}$ \\
\hline
\end{tabular}


iTregs has considerable significance in preventing asthma if generated early enough in life [4]. In addition, Th3 cells that secrete TGF- $\beta$ and IL-10 belong to this subset [17].

\section{Tr1 cells}

The CD4+ T cells that do not express Foxp3, but secret IL-10 and suppress effector functions of Th cells are known as Tr1 cells [4]. It was reported that intravenous immunoglobulin injection in OVA-sensitized and OVAchallenged mice induced production of Tr1 cells from non-Treg cell precursors. These induced Tr1 cells home specifically to the lungs and draining lymph nodes [18]. Their roles in allergen-specific immune reactions include inhibition of functions and migration of effector Th2 cells; and suppression of mast cells, basophils, and eosinophils [8].

\section{CD8 + Tregs}

A subset of Tregs expressing CD8 is rapidly generated from OT-1 CD8 cells in the presence of IL- 4 and IL-12, produce IL-10, and exhibits a unique cell-surface phenotype with coexpression of activation and naive cellassociated markers [9]. They are also observed in tonsils, but rarely detected in peripheral blood. These Foxp3(+) CD8(+) $\mathrm{T}$ cells can be induced in vitro in naive CD8(+) T cells by polyclonal stimulation, which express predominantly CD25(high) and CD28(high), and produce high levels of TNF- $\alpha$, IFN- $\gamma$, and granzyme B. Similarly, tonsillar Foxp3(+)CD8(+) T cells also generate TNF- $\alpha$ and IFN- $\gamma$. However, tonsillar Foxp3(+)CD8(+) T cells do not express IL-17A, mostly CD25 negative, and express low CD127 and CD69. These Foxp3(+)CD8(+) T cells block activation of naive or effector $\mathrm{T}$ cells by direct T-cell-T-cell interaction that antagonizes T-cell-receptor (TCR) signals, and suppress IgG/IgE antibody responses [9], IL-4 expression and the proliferation of CD4(+) T cells [19].

\section{IL-17-producing Foxp3+ Tregs}

It is reported that human peripheral blood and lymphoid tissue, but not thymus contain a significant number of CD4(+)Foxp3(+) T cells that express CCR6 and have the capacity to produce IL-17 upon activation. These cells coexpress Foxp3 and RORgammat transcription factors. The CCR6(+)IL-17-producing Foxp3+ Tregs strongly inhibit the proliferation of CD4(+) responder T cells. Human CCR6(+) IL-17-producing Foxp3+ Tregs are differentiated from CD4(+)Foxp3(+)CCR6(-) Tregs upon T-cell receptor stimulation in the presence of IL-1beta, IL-2, IL-21, IL-23, and human serum [10]. However, a recent report demonstrates that IL-17-producing Foxp3+ Tregs are a novel crossover immune cell population, which could be converted from Tregs to Th17 cells, and associated with a decreased suppressive function of Foxp3 CD4(+) T lymphocytes [20].

\section{Cell signaling of Tregs and potential mechanisms of their actions \\ Cell signaling of Tregs}

As many as 5 subsets of Tregs make Tregs as one of the most complicated T cell groups. Surely, more novel subsets of Tregs will be discovered and their biological functions will be investigated. It is very difficult to understand the reasons why so many subsets of Tregs are needed, and how these cells are generated without looking into the intracellular signaling pathways of these cells, and their migration routes. While the cellular signaling pathways and migration of Tregs remain largely uninvestigated the Figure 1 summarizes the molecular mechanisms involved in cell signaling pathways. Apart from Foxp3 mediated signaling pathways, it was reported that signal transducer and activator of transcription 4 (STAT4) is critical for IL-12 inhibited the development of TGF- $\beta 1$-induced-expressing iTregs, although there is a parallel pathway involving T-bet [21]. It is found that IL-4 supersedes Treg function via the IL-4Ralpha-STAT6 axis, which decreases Foxp3 expression in Tregs and promotes the development of allergic inflammation [22]. Moreover, infectious tolerance mediated by membrane-bound TGF- $\beta$ expressed on Tregs can be compromised by the competing effects of IL-4-induced signaling in naive CD4(+) Th cells [23]. Development of CD8 Tregs is directly induced via STAT4 and STAT6 signaling pathways irrespective of TCR signals [9].

\section{Potential mechanisms of their actions}

Migration to the involved inflammatory area is one of the properties of inflammatory cells including Tregs. It has been found that Foxp3+ Tregs share major nonlymphoid tissue trafficking receptors, such as CCR4, CCR5, CCR6, CXCR3, and CXCR6 with Th17 cells, implicating that these $\mathrm{T}$ cells migrate to and within lymphoid tissues [24]. It has been previously summarized that the mechanisms used by Treg cells to suppress a large number of distinct target cell types can be broadly divided into those that target T cells (suppressor cytokines, IL-2 consumption, granzyme-perforin-induced apoptosis of effector lymphocytes) and those that primarily target antigen-presenting cells (decreased costimulation or decreased antigen presentation) [25]. However, anyone or more mechanisms can be used by Tregs in a defined type of inflammation.

\section{Actions of Tregs on other immune cells}

The suppressive actions of Tregs on other immune cells such as effector T cells, B cells, eosinophils and mast cells may help to explain the reasons why Tregs are capable of controlling acquired immunity. In order to demonstrate the issue more clearly we summarize the actions of Tregs on other cell types in Figure 2. 


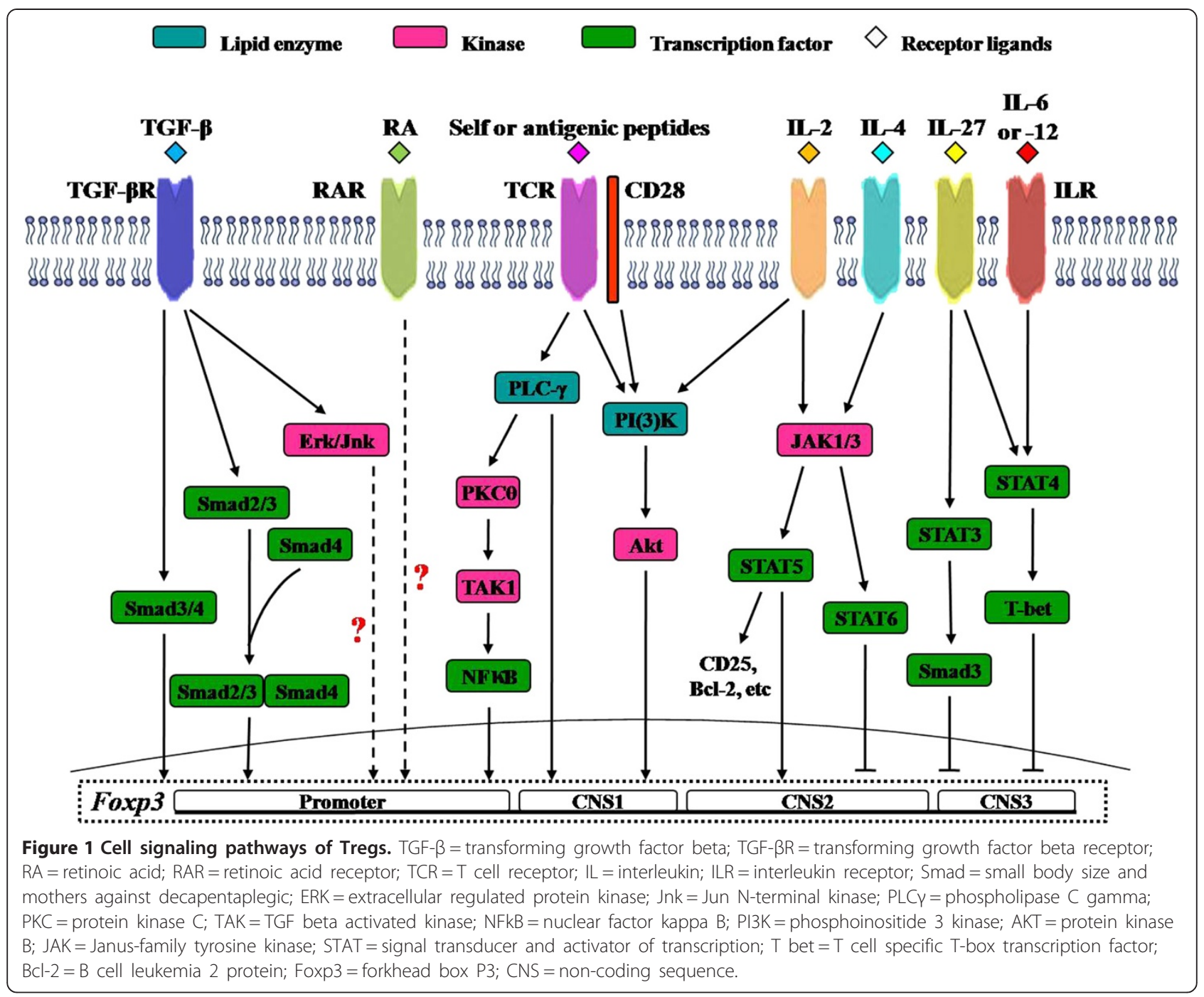

\section{Tregs and mast cells}

Mast cells are essential for immediate allergic reactions, and degranulation of this cell type is a hallmark of allergy [26]. As the classic primary effector cells, mast cells are responsible largely (if not all) for initiation of allergic pathological damage and clinical symptoms. Recently, it has been shown that constitutive Foxp3(+) Treg can control the symptomatic phase of mast cell activation and IgE-dependent anaphylaxis in mice [27], but enhance IL-6 release from mast cells. Inhibition of mast cell degranulation by Tregs appears via OX40/OX40 ligand interactions whereas inhibition of IL-6 release seems via TGF- $\beta$ [28]. In vitro studies demonstrate that IL-4 and TGF- $\beta 1$ had balancing effects on mast cell survival, migration, and FcepsilonRI expression, with each cytokine cancelling the effects of the other. Dysregulation of this balance may impact allergic disease and be amenable to targeted therapy [29].
Tregs and Th cells

On activation, $\mathrm{T}$ cells undergo distinct developmental pathways, attaining specialized properties and effector functions. Th cells are traditionally thought to differentiate into IFN-gamma-secreting Th1, IL-4/IL-5-secreting Th2, and IL-17-secreting Th17 cells. Th1 cells are necessary to clear intracellular pathogens, Th2 cells are important for clearing extracellular antigens, and Th17 cells have been shown to have a crucial role in the induction of autoimmune tissue injury.

It has been reported that TGF-beta1 produced by Foxp3-expressing Tregs is required to inhibit Th1-cell differentiation and promote Th17-cell differentiation [30]. On the other hand, it appears that nitric oxide-induced Tregs inhibit Th17 but not Th1 cell differentiation and function [31]. Tregs can also inhibit IFN- $\gamma$ synthesis without blocking Th1 cell differentiation [32]. These discriminations could be due to different experimental system 


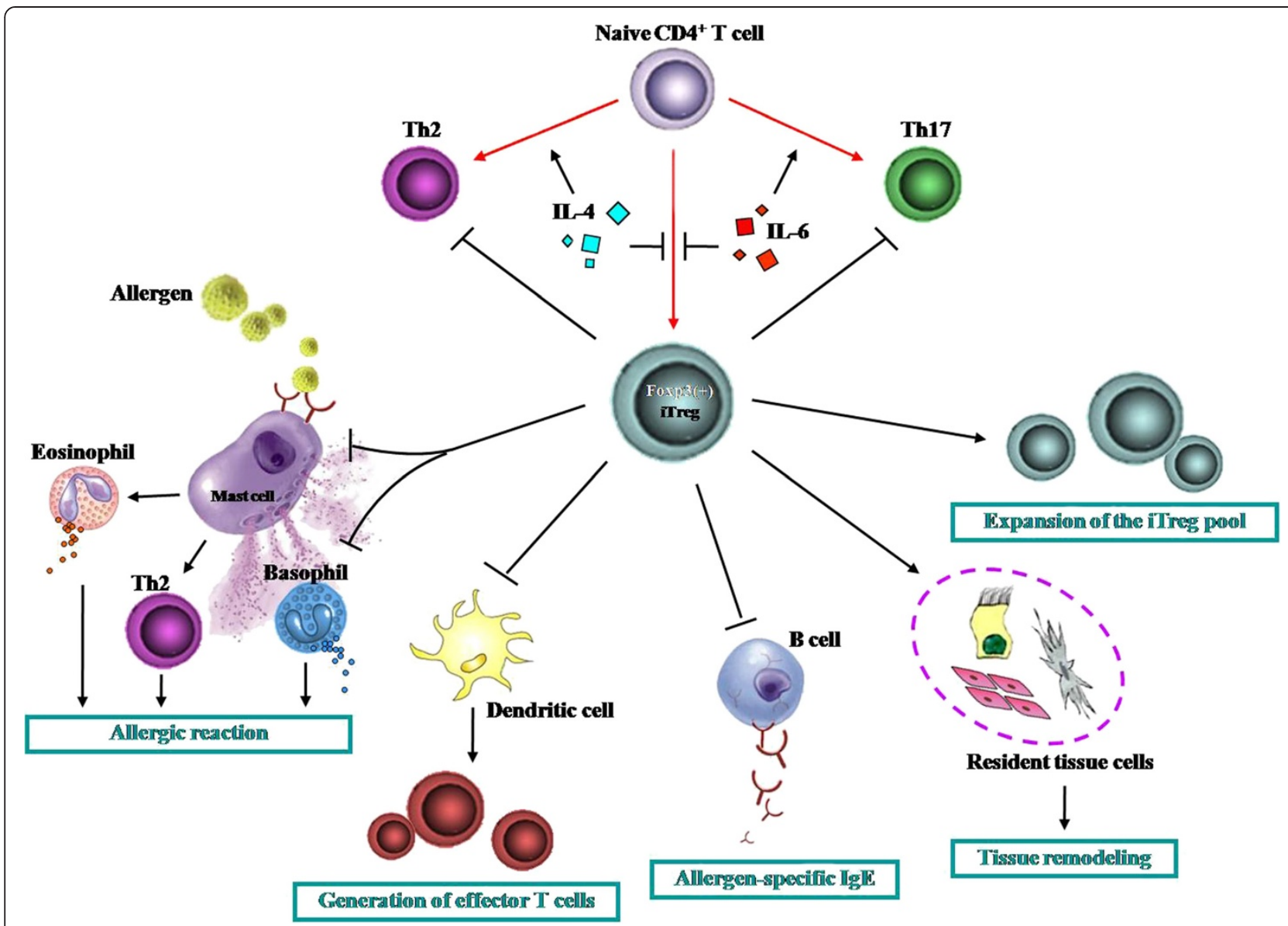

Figure 2 Influence of Tregs on other cell types. Th = helper T cells; iTreg = inducible/adaptive regulatory T cell.

being used in each study. A previous review has described that Tregs can inhibit the development of allergy via suppression of other effector Th1, Th2, Th17 cells [33]. While specific nTregs were highly effective at inhibiting the polarization of naïve $\mathrm{CD} 4(+) \mathrm{T}$ cells into a Th2 phenotype [34], Foxp3(+) Tregs promote Th17 cell development in vivo through regulation of IL-2 [35]. It is found that IL-6 and TGF-beta together induce the differentiation of pathogenic Th17 cells from naive T cells [36].

\section{Tregs and DCs}

DC is the major antigen presenting cells, which play a pivotal role in the sensitization phase of allergic inflammation. It is one of the major targets of Treg-mediated suppression. Some studies have suggested that Tregmediated suppression of DC function is mediated by the interaction of CTLA-4 on Tregs with CD80/CD86 on the DCs resulting in downregulation of CD80/CD86 expression and a decrease in costimulation. A recent study demonstrates further that the major suppressive mechanism of DC function by iTregs is secondary to the effects of IL-10 on MARCH1, an E3 ubiquitin ligase and
CD83 expression [37]. Development of tolerogenic DC phenotype may be of importance for prevention of allergic contact dermatitis. Activated IL-10(+) Treg cells might induce production of the tolerogenic $\mathrm{CD} 11 \mathrm{c}(+)$ DCs, and leads to the generation of hapten-specific CD8(+) Treg cells, which protect against contact hypersensitivity [38].

\section{Tregs and eosinophils}

Eosinophils is one of the secondary effector cells of allergy. It is reported that Tregs are able to inhibit the activity of eosinophils [39], and a negative correlation between the number of eosinophils and the percentage of Foxp3(+) cells is found in BAL from tolerant mice [40].

\section{Tregs and Bregs}

In recent years, regulatory B cell (Breg)s, a subset of B cells which express Foxp3 and secretion of inhibitory cytokine IL-10 and/or TGF- $\beta$ have been discovered [41]. IL-10-producing $B$ cells were the first regulatory B cells to be recognized and were termed 'B10' cells, which is 
CD19(+)CD5(+)IgM(hi)IgD(lo)CD1d(hi) type. Recently, a TGF- $\beta$-producing Breg subset Br3 has been shown to be related to immune tolerance in food allergies. Moreover, Foxp3-expressing B cells have also been identified in humans and may act as Bregs (B-Foxp3 cells). The functional image of regulatory $B$ cells is similar to that of Tregs [42]. The Breg subtypes may be homologous to the Treg subtypes (Br1 cells expressing IL-10, Br3 cells expressing TGF- $\beta$ ), although the Br1 subtype seems to predominate.

Bregs act earlier, facilitating the recruitment of Tregs then disappearing once the Tregs become operational. Therefore, Bregs may play an important role in autoimmune and allergic diseases [43]. Bregs induced pulmonary infiltration of Tregs seems independent of TGF- $\beta$. Because of the proliferative and apoptotic responses of $\mathrm{Br} 1$ and $\mathrm{Br} 3$ cells in immune tolerance in non-IgE-mediated food allergy, reciprocal roles and counter-regulatory mechanisms of Br1 and Br3 responses are suspected [42]. Chronic helminth infections are associated with the expression of regulatory networks such as Tregs and Bregs necessary for downmodulating allergic immune responses to harmless antigens [44]. It is found that helminth Schistosoma mansoni infection induced IL-10-producing CD1d(high) Bregs that could prevent ovalbumin-induced allergic airway inflammation following passive transfer to ovalbumin-sensitized recipients. The transfer of Bregs can reverse established airway inflammation in ovalbuminsensitized mice via Tregs [45].

\section{Contribution of Tregs to allergy}

There is increasing interest in the role of both nTreg and iTreg populations in preventing hypersensitive immune responses and the underlying sensitization to allergens. As early as 2006, it was summerized that Tregs may actively prevent Th2 responses to allergens occurring in healthy non-atopic individuals and that their functions may be impaired in allergic patients [46]. It has been suggested that peripheral T-cell tolerance to environmental antigens is crucial for avoidance of allergy, and aberrant activation of Th2 cells in allergy is secondary to impaired mechanisms of peripheral T-cell tolerance that is normally mediated by antigen-specific T-cell anergy, Tregs and suppressive cytokines, IL-10 and TGF- $\beta$. Therefore, a most appealing therapy for allergic diseases would be an allergen-specific immunotherapy [47] that reduces Th2 cytokine production and promotes induction of anergy, Treg and suppressor cytokines [48]. Very recently, it is found that tonsil pDCs have the ability to generate functional CD4(+)CD25(+) CD127(-)Foxp3(+) Tregs with suppressive property from naive $\mathrm{T}$ cells, and that functional allergen-specific Tregs are identified both in lingual and in palatine tonsils. Since lingual tonsil is anatomically big and remains lifelong intact, it may serve as potential first-line organs of oral tolerance against allergens [49]. In order to further understand the roles of Tregs in allergy, we summarized the involvement of Tregs in different allergic diseases (Table 2).

\section{Tregs in allergic dermatitis}

Very recently, in a murine atopic dermatitis model, the numbers of nTregs are found increase in the allergenexposed skin area and in the secondary lymphoid organs, and CD103+ effector/memory Tregs are observed to expand gradually in the lymph nodes throughout the sensitization protocol. The depletion of Tregs leads to significantly exacerbated skin inflammation, including increased recruitment of inflammatory cells and expression of Th2 cytokines, as well as elevated serum IgE levels [50]. It is also found that the ratio of Foxp3+/CD4+ cells appears skewed towards effector $\mathrm{T}$ cells associated with inflammation in the margin and centre of the psoriatic plaque, and that increased IL-17 is mostly related to mast cells, and only sporadically to T cells [51].

\section{Tregs in allergic rhinitis}

A study which investigated allergen-induced Th2, Th1 and Treg immune responses in peripheral blood mononuclear cells (PBMC) and their association with symptom improvement in allergic rhinitis patients after 3 years of SIT shows that both IL-4 expression and the IL-4/IFNgamma ratio are decreased in patients with a good therapeutic outcome after 1 year of SIT, whereas the induced Treg and Th1 responses persists over 3 years of SIT [52].

\section{Tregs in allergic lower airway inflammation}

It was reported in 2007 that diverse populations of Tregs play an important role in regulating Th2 responses to allergens, maintaining functional tolerance. In experimental asthma models, Tregs can suppress Th2 responses to allergen, airway eosinophilia, mucous hypersecretion, and airway hyperresponsiveness (AHR) [53]. After a long-term aerosol challenge, referred to as local inhalational tolerance, ovalbumin induced allergic airway inflammation resolves with increased number of Tregs, reduced number of $\mathrm{T}$ and $\mathrm{B}$ lymphocytes in bronchoalveolar lavage fluid and hilar lymph node [54]. Depletion of Tregs during the sensitizing phase of an active immune response led to a dramatic exacerbation of allergic airway inflammation in mice, suggesting an essential role of Tregs in regulating immune responses against allergens as early as the sensitization phase via maintenance of functional tolerance [55]. Furthermore, antigen-induced airway hyperreactivity can be completely suppressed by adoptive transfer of Tregs overexpressing active TGF- $\beta 1$ and IL-10 [56]. Recent work has demonstrated that Foxp3 expression is reduced and CD25(hi) Treg-suppressive 
Table 2 Involvement of regulatory T cell (Treg)s in different allergic diseases

\begin{tabular}{|c|c|c|}
\hline Disease & Location & Involvement of Tregs \\
\hline Allergic dermatitis & Skin, the secondary lymphoid organs & $\begin{array}{l}\text { The depletion of Tregs leads to significantly exacerbated skin inflammation } \\
\text { as well as elevated serum lgE levels [50]. }\end{array}$ \\
\hline Allergic rhinitis & Tonsil, Blood & $\begin{array}{l}\text { Potential first-line organs of oral tolerance against allergens [49]; allergic } \\
\text { rhinitis patients with a good therapeutic outcome after } 1 \text { year of SIT, the } \\
\text { induced Treg and Th1 responses persist over } 3 \text { years of SIT [52]. }\end{array}$ \\
\hline Allergic airway inflammation & Blood, peribronchial lymph nodes & $\begin{array}{l}\text { Foxp3 expression is reduced and CD25(hi) Treg-suppressive function is } \\
\text { deficient in asthma. Corticosteroids and allergen immunotherapy act on } \\
\text { Tregs, in part to increase IL-10 production, while vitamin D3 and long-acting } \\
\text { beta-agonists enhance Tr1 cell function [57]. Heligmosomoides polygyrus } \\
\text { infection is associated with elevated numbers of Tregs in airway challenged } \\
\text { mice [60], efficiently protects mice from asthma by induction of accumulation } \\
\text { of highly suppressive Tregs in the lungs [61]. }\end{array}$ \\
\hline
\end{tabular}

SIT = specific immunotherapy.

function is deficient in asthma. Existing therapies including corticosteroids and allergen immunotherapy act on Tregs, in part to increase IL-10 production, while vitamin D3 and long-acting beta-agonists enhance $\operatorname{Tr} 1$ cell function [57]. In addition, Treg-specific ablation of the E3 ubiquitin ligase Itch in mice causes massive multiorgan lymphocyte infiltration and development of severe antigen-induced pulmonary inflammation, which unveils a mechanism of Treg acquisition of Th2-like properties that is independent of Foxp3 function and Treg cell stability [58]. All these findings indicate the pivotal role of Tregs in allergic airway inflammation. It is recognized that IL-2 is needed to maintain Foxp3+ Tregs in the periphery [4]. Therefore, a cytokine:antibody complexes of IL-2 and anti-IL-2 mAb reduce the severity of allergen-induced inflammation in the lung by expanding Tregs in vivo. Following IL-2:anti-IL-2 treatment, airway inflammation and eosinophilia is dampened, and mucus production, AHR to methacholine and parenchymal tissue inflammation are also dramatically reduced. The IL-2:anti-IL-2 treatment is dependent on Treg-derived IL-10, and suggests that endogenous Treg therapy may be a useful tool to combat asthma [59].

It has long been observed that some helminth infections are negatively associated with the prevalence of allergic disorders. Using heligmosomoides polygyrus (H. polygyrus) in a murine model of allergic airway disease and of atopic dermatitis, it is found that mice concomitantly infected with $H$. polygyrus diminishes eosinophil and lymphocyte recruitment into the lungs and decreased allergen-specific IgE levels. The worm infection is associated with significantly elevated numbers of Tregs in peribronchial lymph nodes in airway challenged mice. On the other hand, mast cell recruitment is significantly increased, and Tregs are basically absent in eczematous skin and remained the same in skin-draining lymph nodes in worm-infected allergic dermatitis mice, suggesting that infection with the gastrointestinal nematode leads to significant inhibition of mucosa-associated but not cutaneous allergic reactions [60]. Moreover, it has been reported recently that a bacterial pathogen Helicobacter pylori (H. pylori) infection efficiently protects mice from asthma by induction of impaired maturation of lung-infiltrating DCs and the accumulation of highly suppressive Tregs in the lungs. Since systemic Treg depletion abolishes asthma protection it suggests that the action of $\mathrm{H}$. pylori is via Tregs [61]. The B subunit of E. coli heat-labile enterotoxin (EtxB) treatment diminishes eosinophilia in bronchoalveolar lavage, reduces OVA-specific IgE and IL-4 production locally and systemically, and reduces AHR in a mouse model of asthma. EtxB induces a dose-dependent increase in OVA-specific CD4(+)Foxp3(+) T cells in the lung and systemically, suggesting that the action of. EtxB on the mice is through iTregs [62].

\section{Roles of Tregs in treatment of allergy}

It has been recognized that Tregs are involved in the treatment of allergic diseases, which helps to explain some therapeutic mechanisms that puzzle us for decades. The potential roles of Tregs in anti-allergic therapies are summarized in Table 3.

\section{In specific immunotherapy}

Antigen specific respiratory tolerance is mediated by lung DCs producing IL-10, which induce the development of Tregs. The development of respiratory tolerance also depends on co-stimulation (CD86, and the ICOSICOSL pathway). Although exposure of the respiratory mucosa to some pathogenic agents (especially virus, and endotoxin) is associated with asthma exacerbations, microbial exposure may also promote mucosal tolerance and protection against the development of allergic diseases. Mucosal-based immunotherapy has been already used as an alternative form of allergen delivery in immunotherapy [63]. Allergen-specific immunotherapy is the only treatment that leads to reverse established allergic disease and lifelong tolerance to previously diseasecausing allergens by restoring normal immunity against allergens. Tregs are involved in preventing sensitization 
Table 3 Therapeutic actions of regulatory T cell (Treg)s in allergic diseases

\begin{tabular}{ll}
\hline Therapy & Action of Tregs \\
\hline SIT & Suppression of T cell responses to the T-cell epitopes of major allergens. Autocrine action of IL-10 and/or TGF- $\beta$, \\
which are produced by antigen-specific Tregs. They may suppress IgE production and induce IgG4 and IgA \\
production against allergens [65]. Histamine released from mast cells and basophils may efficiently contribute to \\
immunoregulation, and affect Tregs [6]. Der $p$ immunotherapy causes increased number of Treg cells, and \\
elevated IL-10 production. IL-10(+) Tregs may respond to Der p-2 and down-regulate NF-kB/p65 expression in \\
PBMC to maintain immune tolerance during SIT [66].
\end{tabular}

Allergen extracts administered via the sublingual route are long retained at mucosal level, where the allergen molecules are captured by DCs, following their migration in the draining lymph nodes, presented to T cells to generate iTregs [64]. SLIT causes the absence of effectors cells, such as mast cells, basophils and eosinophils in the oral mucosa of allergic subjects. Skewing of allergic-specific effector T cells to a $\operatorname{Tr} 1$ phenotype appears to be a critical event in successful allergen-specific immunotherapy and glucocorticoids and beta2-agonists treatment [8].

Bacteria therapy Lactobacilli prime of DCs to drive the development of Tregs. These Tregs produce increased IL-10 inhibiting the proliferation of bystander T cells [4].

Treg therapy

Transfer of OVA peptide-specific CD4 + CD25+ Tregs to OVA-sensitized mice reduces AHR, recruitment of eosinophils, and Th2 cytokine expression in the lung after allergen challenge [70].

$\mathrm{SIT}=$ specific immunotherapy; Der $\mathrm{p}=$ Dermatophagoides pteronyssinus; PBMC = peripheral blood mononuclear cells; $\mathrm{SLTT}=$ sublingual immunotherapy; AHR= airway hyperresponsiveness; OVA = ovalbumin.

to allergens by suppression of $\mathrm{T}$ cell responses to the T-cell epitopes of major allergens. It is initiated by the autocrine action of IL-10 and/or TGF- $\beta$, which are produced by antigen-specific Tregs. They may suppress IgE production and induce IgG4 and IgA production against allergens. In addition, histamine released from mast cells and basophils may efficiently contribute to immunoregulation during specific immunotherapy, and affect Treg cells and the production of their cytokines via histamine receptor 2 [6].

Sublingual immunotherapy (SLIT) is an effective and safe treatment for respiratory allergy. Studies of pharmacokinetics shows that allergen extracts administered via the sublingual route are not directly absorbed by the oral mucosa but are long retained at mucosal level, where the allergen molecules are captured by DCs, following their migration in the draining lymph nodes, presented to $\mathrm{T}$ cells to generate iTregs. This is at least for the long-term effects, and for the short-term efficacy, observed with ultrarush or coseasonal treatment, a downregulation of mast cells resulting in hyporeactivity at the peak of the pollen season may be suggested [64]. Indeed, SLIT causes the absence of effectors cells, such as mast cells, basophils and eosinophils in the oral mucosa of allergic subjects. Skewing of allergic-specific effector $\mathrm{T}$ cells to a $\operatorname{Tr} 1$ phenotype appears to be a critical event in successful allergen-specific immunotherapy and glucocorticoids and beta2-agonists treatment. Tr1 suppresses Th2 cells and effector cells of allergic inflammation, such as eosinophils, mast cells, basophils, through producing IL-10 [8], and TGF- $\beta$ [65]. The increased levels of IL-10 and TGF- $\beta$ that are produced by Tregs potently suppress IgE production, while simultaneously increasing production of non-inflammatory isotypes IgG4 and IgA, respectively [65]. NF- $\mathrm{kB}$ acts as a mater switch for allergic inflammation. Dermatophagoides pteronyssinus
(Der p) immunotherapy causes increased numbers of Foxp3+ CD4+ Tregs, and elevated IL-10 production with decreased IRAK-1 and NF-kB/p65 nuclear translocation. IL-10(+) Tregs may respond to Der $\mathrm{p}-2$ and down-regulate NF- $\mathrm{kB} / \mathrm{p} 65$ expression in peripheral blood mononuclear cells to maintain immune tolerance during immunotherapy [66].

\section{In other therapies}

Parasite infection does not prevent allergen sensitisation, but restricts the Th2 effector phase responsible for inflammation. Suppression of allergic inflammation can be transferred by Tregs from an infected, allergen-naïve animal to an uninfected, sensitized recipient [67]. This may due to at least in part that infections increase the activity of Tregs, which suppress effector mechanisms of both Th1 and Th2 types [68].

Using green fluorescent protein (GFP)-Foxp3 knock-in reporter mice, it is found that intravenous immunoglobulin (IVIG) markedly improves OVA-induced airway hyperresponsiveness characterized by 4- to 6-fold enhancement in Tregs in pulmonary and associated lymphoid tissues. Induction of Tregs is mediated by tolerogenic DCs generated after IVIG exposure. IVIG-primed DCs express altered Notch ligands, including increased Delta4 and reduced Jagged-1 levels, reflecting decreased Th2 polarization. Furthermore, IVIG-primed DCs can stimulate Treg differentiation from uncommitted Foxp3(-) CD4(+) T cells ex vivo [18]. It is now well recognized that microorganisms can induce the generation of suppressive cytokines TGF-beta and IL-10 [4]. Two different species of lactobacilli, Lactobacillus reuteri and Lactobacillus casei are able to prime of monocyte-derived immunomodulation DCs to drive the development of Tregs by binding the C-type lectin $\mathrm{DC}$-specific intercellular adhesion molecule 3-grabbing non-integrin (DC-SIGN). 
These Tregs produce increased level of IL-10 and are capable of inhibiting the proliferation of bystander T cells in an IL-10-dependent fashion. The probiotic bacteria might be used in the treatment of a number of inflammatory diseases, including atopic dermatitis and Crohn's disease [69].

Transfer of OVA peptide-specific CD4 + CD25+ Tregs to OVA-sensitized mice reduces AHR, recruitment of eosinophils, and Th2 cytokine expression in the lung after allergen challenge. This suppression is dependent on IL-10 because increased lung expression of IL-10 is detected after transfer of Tregs, and regulation is reversed by anti-IL-10 receptor antibody. Tregs can suppress the Th2 cell-driven response to allergen in vivo by an IL-10-dependent mechanism but that IL-10 production by the Tregs themselves is not required for such suppression [70].

\section{Tregs in early life}

The concept of iTregs has considerable significance in preventing asthma if generated early enough in life. This is because cytokines such as IL-4 and IL-6 inhibit Foxp3 induction in naive $\mathrm{CD} 4+\mathrm{T}$ cells and therefore de novo generation of Tregs can be expected to be less efficient when it is concomitant with effector cell development in response to an allergen. However, if iTregs can be induced, the process of infectious tolerance would facilitate expansion of the iTreg pool. There may be an opportunity in early life in the context of a relatively immature immune system that is permissive for the generation of iTregs specific to a spectrum of allergens that would regulate asthma for lifelong [4]. A recent study shows that the timothy- and birch-allergic mothers respond with increased proliferation and/or IL-4 production towards timothy and birch extract. However, cord blood mononuclear cell proliferation, phenotype of $\mathrm{T}$ cells, Foxp3(+) Tregs and B cells in response to the allergens are not affected by the allergic status of the mother [71]. Fetal exposures have been investigated as risk factors of early life allergic disease, and it is showed that nTreg levels during pregnancy in venous blood samples vary in association with both dog and cat exposure and atopic status [72].

\section{Summary}

Tregs have been emerging as key focus in the sensitization phase of the pathogenesis of allergy. Through acting upon other cell types, Tregs seem to control acquired immunity in the body. Based upon the information available, we propose that Tregs should be classified into 5 subgroups: nTregs including ICOS)(+) Tregs, iTregs, Tr1 cells, CD8(+) Tregs, and IL-17-producing Tregs. These cells share some common features including expression of Foxp3, and secretion of inhibitory cytokine IL-10 and/or
TGF- $\beta$. However, signaling pathways of Tregs remain largely uninvestigated.

In recent years, there is increasing interest in the role of both nTreg and iTreg populations in preventing hypersensitive immune responses and the underlying sensitization to allergens. Since eliminated actions of Tregs may increase the chance for sensitive individuals to suffer from allergy, we summarized the involvement of Tregs in different allergic diseases. It has been suggested that peripheral $\mathrm{T}$-cell tolerance to environmental antigens is crucial for avoidance of allergy. Therefore a most appealing therapy for allergic diseases would be SIT that reduces Th2 cytokine production and promotes induction of $\mathrm{T}$ cell anergy, Tregs and suppressor cytokines. Tregs are also involved in other immune therapies such as parasite or bacterial infections to treat allergy.

In conclusion, at least 5 subsets of Tregs are derived from naive $\mathrm{T}$ cells under different conditions, but exact role of each subtype of them in controlling allergic diseases remains obscure. It is widely accepted that Tregs play a pivotal role in the development of allergy, particularly in the sensitization phase. Therefore targeting Tregs can be a useful therapy for prevention and treatment of allergy.

\section{Competing interests}

The authors declare that there is no competing interests regarding the publication of this article.

\section{Authors' contribution}

$\mathrm{HY} Z$ created the tables and drafted the primary manuscript. H K and XN Z drew the figures. LY G and XY S collected some data. SH H designed and corrected the manuscript. All authors have read and approved the final manuscript.

\section{Acknowledgement}

This project was sponsored by the grants from the Major State Basic Research Program of China (973 Program) (No. 2013CB530501); the National Natural Science Foundation of China (No. 81241135, 81060250, 81030054, 81001428, 81172836); State Scholarship Fund of China (201208460001); Outstanding Research Team Project Funded by the Liaoning Provincial Education Department (LT2013017); Outstanding Scholar Project Funded by the Liaoning Provincial Education Department (2013222); Translational Medicine Research Centre Funded by the Liaoning Provincial Science and Technology Department (201341).

\section{Author details}

Allergy and Clinical Immunology Research Centre, the First Affiliated Hospital of Liaoning Medical University, No. 2, Section 5, Renmin Street, Guta District, Jinzhou, Liaoning 121001, People's Republic of China. ${ }^{2}$ Central Laboratory, Suzhou Xiangcheng People's Hospital, Suzhou 215131, China. ${ }^{3}$ Department of Respiratory Medicine, the First Affiliated Hospital of Nanjing Medical University, Nanjing 210029, China.

\section{Received: 4 February 2014 Accepted: 28 March 2014}

Published: 12 May 2014

\section{References}

1. Warner JO, Kaliner MA, Crisci CD, Del Giacco S, Frew AJ, Liu GH, Maspero J, Moon HB, Nakagawa T, Potter PC, Rosenwasser $\amalg$, Singh AB, Valovirta E, Van Cauwenberge P, World Allergy Organization Specialty and Training Council: Allergy practice worldwide: a report by the World Allergy Organization Specialty and Training Council. Int Arch Allergy Immunol 2006, 139(2):166-174. 
2. Barnes PJ: Pathophysiology of allergic inflammation. Immunol Rev 2011, 242(1):31-50.

3. Afzali B, Lombardi G, Lechler RI, Lord GM: The role of T helper 17 (Th17) and regulatory $T$ cells (Treg) in human organ transplantation and autoimmune disease. Clin Exp Immunol 2007, 148(1):32-46

4. Ray A, Khare A, Krishnamoorthy N, Qi Z, Ray P: Regulatory T cells in many flavors control asthma. Mucosal Immunol 2010, 3(3):216-229.

5. Sogut A, Yilmaz O, Kirmaz C, Ozbilgin $\mathrm{K}$, Onur E, Celik O, Pinar E, Vatansever $\mathrm{S}$, Dinc G, Yuksel H: Regulatory-T, T-helper 1, and T-helper 2 cell differentiation in nasal mucosa of allergic rhinitis with olive pollen sensitivity. Int Arch Allergy Immunol 2012, 157(4):349-353.

6. Jutel M, Akdis M, Blaser K, Akdis CA: Are regulatory T cells the target of venom immunotherapy? Curr Opin Allergy Clin Immunol 2005, 5(4):365-369.

7. Ito T, Hanabuchi S, Wang YH, Park WR, Arima K, Bover L, Qin FX, Gilliet M, Liu YJ: Two functional subsets of FOXP3+ regulatory T cells in human thymus and periphery. Immunity 2008, 28(6):870-880.

8. Wu K, Bi Y, Sun K, Wang C: IL-10-producing type 1 regulatory T cells and allergy. Cell Mol Immunol 2007, 4(4):269-275.

9. Noble A, Giorgini A, Leggat JA: Cytokine-induced IL-10-secreting CD8 T cells represent a phenotypically distinct suppressor T-cell lineage. Blood 2006, 107(11):4475-4483.

10. Voo KS, Wang $Y H$, Santori FR, Boggiano C, Wang $Y H$, Arima $K$, Bover $L$, Hanabuchi S, Khalili J, Marinova E, Zheng B, Littman DR, Liu YJ: Identification of IL-17-producing FOXP3+ regulatory T cells in humans. Proc Natl Acad Sci U S A 2009, 106(12):4793-4798.

11. Ostroukhova M, Ray A: CD25+ T cells and regulation of allergen-induced responses. Curr Allergy Asthma Rep 2005, 5(1):35-41.

12. Akdis CA, Akdis M: Mechanisms and treatment of allergic disease in the big picture of regulatory T cells. J Allergy Clin Immunol 2009, 123(4):735-746. quiz 747-738

13. Tulic MK, Andrews D, Crook ML, Charles A, Tourigny MR, Mogbel R, Prescott SL: Changes in thymic regulatory T-cell maturation from birth to puberty: differences in atopic children. J Allergy Clin Immunol 2012, 129(1):199-206. e191-194.

14. Seddiki N, Santner-Nanan B, Martinson J, Zaunders J, Sasson S, Landay A, Solomon M, Selby W, Alexander SI, Nanan R, Kelleher A, Fazekas de St Groth B: Expression of interleukin (IL)-2 and IL-7 receptors discriminates between human regulatory and activated T cells. J Exp Med 2006, 203(7):1693-1700.

15. Vocanson M, Rozieres A, Hennino A, Poyet G, Gaillard V, Renaudineau S, Achachi A, Benetiere J, Kaiserlian D, Dubois B, Nicolas JF: Inducible costimulator (ICOS) is a marker for highly suppressive antigen-specific $T$ cells sharing features of $\mathrm{TH} 17 / \mathrm{TH} 1$ and regulatory $\mathrm{T}$ cells. J Allergy Clin Immunol 2010, 126(2):280-289. 289.e281-287.

16. Kretschmer K, Apostolou I, Hawiger D, Khazaie K, Nussenzweig MC, von Boehmer $\mathrm{H}$ : Inducing and expanding regulatory $\mathrm{T}$ cell populations by foreign antigen. Nat Immunol 2005, 6(12):1219-1227.

17. Peterson RA: Regulatory T-cells: diverse phenotypes integral to immune homeostasis and suppression. Toxicol Pathol 2012, 40(2):186-204.

18. Massoud AH, Guay J, Shalaby KH, Bjur E, Ablona A, Chan D, Nouhi Y, McCusker CT, Mourad MW, Piccirillo CA, Mazer BD: Intravenous immunoglobulin attenuates airway inflammation through induction of forkhead box protein 3-positive regulatory T cells. J Allergy Clin Immunol 2012, 129(6):1656-1665. e1653.

19. Siegmund K, Ruckert B, Ouaked N, Burgler S, Speiser A, Akdis CA, SchmidtWeber CB: Unique phenotype of human tonsillar and in vitroinduced FOXP3 + CD8+ T cells. J Immunol (Baltimore, Md: 1950) 2009, 182(4):2124-2130.

20. Ueno A, Jijon $\mathrm{H}$, Chan $\mathrm{R}$, Ford $\mathrm{K}$, Hirota $\mathrm{C}$, Kaplan GG, Beck PL, lacucci M, Fort Gasia M, Barkema HW, Panaccione R, Ghosh S: Increased prevalence of circulating novel IL-17 secreting Foxp3 expressing CD4+ T cells and defective suppressive function of circulating Foxp3+ regulatory cells support plasticity between Th17 and regulatory T cells in inflammatory bowel disease patients. Inflamm Bowel Dis 2013, 19(12):2522-2534.

21. O'Malley JT, Sehra S, Thieu VT, Yu Q, Chang HC, Stritesky GL, Nguyen ET, Mathur AN, Levy DE, Kaplan MH: Signal transducer and activator of transcription 4 limits the development of adaptive regulatory T cells. Immunology 2009, 127(4):587-595.

22. Wang $Y$, Souabni A, Flavell RA, Wan $Y Y$ : An intrinsic mechanism predisposes Foxp3-expressing regulatory $T$ cells to Th2 conversion in vivo. J Immunol (Baltimore, Md: 1950) 2010, 185(10):5983-5992.
23. Pillemer BB, Qi Z, Melgert B, Oriss TB, Ray P, Ray A: STAT6 activation confers upon $T$ helper cells resistance to suppression by regulatory $T$ cells. J Immunol (Baltimore, Md: 1950) 2009, 183(1):155-163.

24. Lim HW, Lee J, Hillsamer P, Kim CH: Human Th17 cells share major trafficking receptors with both polarized effector T cells and FOXP3+ regulatory T cells. J Immunol (Baltimore, Md: 1950) 2008, 180(1):122-129.

25. Shevach EM: Mechanisms of foxp3+ T regulatory cell-mediated suppression. Immunity 2009, 30(5):636-645.

26. He S, Zhang H, Zeng $X$, Yang P: Self-amplification mechanisms of mast cell activation: a new look in allergy. Curr Mol Med 2012, 12(10):1329-1339.

27. Kanjarawi R, Dy M, Bardel E, Sparwasser T, Dubois B, Mecheri S, Kaiserlian D: Regulatory CD4 + Foxp3+ T cells control the severity of anaphylaxis. PLOS One 2013, 8(7):e69183.

28. Ganeshan K, Bryce PJ: Regulatory T cells enhance mast cell production of IL-6 via surface-bound TGF-beta. J Immunol (Baltimore, Md: 1950) 2012, 188(2):594-603.

29. Macey MR, Sturgill JL, Morales JK, Falanga YT, Morales J, Norton SK, Yerram N, Shim H, Fernando J, Gifillan AM, Gomez G, Schwartz L, Oskeritzian C, Spiegel S, Conrad D, Ryan JJ: IL-4 and TGF-beta 1 counterbalance one another while regulating mast cell homeostasis. J Immunol (Baltimore, Md: 1950) 2010, 184(9):4688-4695.

30. Li MO, Wan YY, Flavell RA: T cell-produced transforming growth factor-beta 1 controls $T$ cell tolerance and regulates Th1- and Th17-cell differentiation. Immunity 2007, 26(5):579-591.

31. Niedbala W, Besnard AG, Jiang HR, Alves-Filho JC, Fukada SY, Nascimento D, Mitani A, Pushparaj P, Alqahtani MH, Liew FY: Nitric oxide-induced regulatory $\mathrm{T}$ cells inhibit Th17 but not Th1 cell differentiation and function. J Immunol (Baltimore, Md: 1950) 2013, 191(1):164-170.

32. Sojka DK, Fowell DJ: Regulatory T cells inhibit acute IFN-gamma synthesis without blocking T-helper cell type 1 (Th1) differentiation via a compartmentalized requirement for IL-10. Proc Natl Acad Sci U S A 2011, 108(45):18336-18341.

33. Palomares O, Yaman G, Azkur AK, Akkoc T, Akdis M, Akdis CA: Role of Treg in immune regulation of allergic diseases. Eur J Immunol 2010, 40(5):1232-1240.

34. Girtsman $T$, Jaffar Z, Ferrini M, Shaw P, Roberts K: Natural Foxp3(+) regulatory $\mathrm{T}$ cells inhibit Th2 polarization but are biased toward suppression of Th17-driven lung inflammation. J Leukoc Biol 2010, 88(3):537-546.

35. Chen Y, Haines CJ, Gutcher I, Hochweller K, Blumenschein WM, McClanahan T, Hammerling G, Li MO, Cua DJ, McGeachy MJ: Foxp3(+) regulatory T cells promote Thelper 17 cell development in vivo through regulation of interleukin-2. Immunity 2011, 34(3):409-421.

36. Bettelli E, Carrier Y, Gao W, Korn T, Strom TB, Oukka M, Weiner HL, Kuchroo VK: Reciprocal developmental pathways for the generation of pathogenic effector TH17 and regulatory T cells. Nature 2006, 441(7090):235-238.

37. Chattopadhyay G, Shevach EM: Antigen-specific induced T regulatory cells impair dendritic cell function via an IL-10/MARCH1-dependent mechanism. J Immunol (Baltimore, Md: 1950) 2013, 191(12):5875-5884.

38. Luckey U, Schmidt T, Pfender N, Romer M, Lorenz N, Martin SF, Bopp T, Schmitt E, Nikolaev A, Yogev N, Waisman A, Jakob T, Steinbrink K: Crosstalk of regulatory $T$ cells and tolerogenic dendritic cells prevents contact allergy in subjects with low zone tolerance. J Allergy Clin Immunol 2012, 130(3):781-797. e711.

39. Braga M, Quecchia C, Cavallucci E, Di Giampaolo L, Schiavone C, Petrarca C, Di Gioacchino M: T regulatory cells in allergy. Int J Immunopathol Pharmacol 2011, 24(1):55 s-64s.

40. Adel-Patient K, Wavrin S, Bernard H, Meziti N, Ah-Leung S, Wal JM: Oral tolerance and Treg cells are induced in BALB/c mice after gavage with bovine beta-lactoglobulin. Allergy 2011, 66(10):1312-1321.

41. Lundy SK, Berlin AA, Martens TF, Lukacs NW: Deficiency of regulatory B cells increases allergic airway inflammation. Inflammation research: official Journal of the European Histamine Research Society [et al] 2005, 54(12):514-521.

42. Noh G, Lee JH: Regulatory B cells and allergic diseases. Allergy Asthma Immunol Res 2011, 3(3):168-177.

43. Berthelot JM, Jamin C, Amrouche K, Le Goff B, Maugars Y, Youinou P: Regulatory $B$ cells play a key role in immune system balance. Joint Bone Spine 2013, 80(1):18-22.

44. Smits HH, Everts B, Hartgers FC, Yazdanbakhsh M: Chronic helminth infections protect against allergic diseases by active regulatory processes. Curr Allergy Asthma Rep 2010, 10(1):3-12. 
45. Amu S, Saunders SP, Kronenberg M, Mangan NE, Atzberger A, Fallon PG: Regulatory $B$ cells prevent and reverse allergic airway inflammation via FoxP3-positive T regulatory cells in a murine model. J Allergy Clin Immunol 2010, 125(5):1114-1124. e1118.

46. Xystrakis E, Boswell SE, Hawrylowicz CM: T regulatory cells and the control of allergic disease. Expet Opin Biol Ther 2006, 6(2):121-133.

47. Ziora D, Sitek $P$, Machura E, Ziora K: Bronchial asthma in obesity-a distinct phenotype of asthma? Pneumonol Alergol Pol 2012, 80(5):454-462.

48. Li L, Boussiotis VA: Control and regulation of peripheral tolerance in allergic inflammatory disease: therapeutic consequences. Chem Immunol Allergy 2008, 94:178-188.

49. Palomares O, Ruckert B, Jartti T, Kucuksezer UC, Puhakka T, Gomez E, Fahrner HB, Speiser A, Jung A, Kwok WW, Kalogjera L, Akdis M, Akdis CA: Induction and maintenance of allergen-specific FOXP3+ Treg cells in human tonsils as potential first-line organs of oral tolerance. J Allergy Clin Immunol 2012, 129(2):510-520. 520.e511-519.

50. Fyhrquist N, Lehtimaki S, Lahl K, Savinko T, Lappetelainen AM, Sparwasser T, Wolff $H$, Lauerma A, Alenius H: Foxp3+ cells control Th2 responses in a murine model of atopic dermatitis. J Investig Dermatol 2012, 132(6):1672-1680

51. Keijsers RR, van der Velden HM, van Erp PE, de Boer-van Huizen RT, Joosten I, Koenen HJ, van de Kerkhof PC: Balance of Treg vs. T-helper cells in the transition from symptomless to lesional psoriatic skin. $\mathrm{Br} J$ Dermatol 2013, 168(6):1294-1302.

52. Nieminen K, Laaksonen K, Savolainen J: Three-year follow-up study of allergen-induced in vitro cytokine and signalling lymphocytic activation molecule mRNA responses in peripheral blood mononuclear cells of allergic rhinitis patients undergoing specific immunotherapy. Int Arch Allergy Immunol 2009, 150(4):370-376.

53. Larche M: Regulatory T cells in allergy and asthma. Chest 2007, 132(3):1007-1014.

54. Carson WF, Guernsey LA, Singh A, Vella AT, Schramm CM, Thrall RS: Accumulation of regulatory $T$ cells in local draining lymph nodes of the lung correlates with spontaneous resolution of chronic asthma in a murine model. Int Arch Allergy Immunol 2008, 145(3):231-243.

55. Baru AM, Hartl A, Lahl K, Krishnaswamy JK, Fehrenbach H, Yildirim AO, Garn H, Renz H, Behrens GM, Sparwasser T: Selective depletion of Foxp3+ Treg during sensitization phase aggravates experimental allergic airway inflammation. Eur J Immunol 2010, 40(8):2259-2266.

56. Presser K, Schwinge D, Wegmann M, Huber S, Schmitt S, Quaas A, Maxeiner JH, Finotto S, Lohse AW, Blessing M, Schramm C: Coexpression of TGF-beta1 and IL-10 enables regulatory T cells to completely suppress airway hyperreactivity. J Immunol (Baltimore, Md: 1950) 2008 , 181(11):7751-7758.

57. Robinson DS: Regulatory T cells and asthma. Clin Exp Allergy 2009, 39(9):1314-1323.

58. Jin HS, Park Y, Elly C, Liu YC: Itch expression by Treg cells controls Th2 inflammatory responses. J Clin Investig 2013, 123(11):4923-4934.

59. Wilson MS, Pesce JT, Ramalingam TR, Thompson RW, Cheever A, Wynn TA: Suppression of murine allergic airway disease by IL-2:anti-IL-2 monoclonal antibody-induced regulatory T cells. J Immunol (Baltimore, Md: 1950) 2008, 181(10):6942-6954.

60. Hartmann S, Schnoeller C, Dahten A, Avagyan A, Rausch S, Lendner M, Bocian C, Pillai S, Loddenkemper C, Lucius R, Worm M, Hamelmann E: Gastrointestinal nematode infection interferes with experimental allergic airway inflammation but not atopic dermatitis. Clin Exp Allergy 2009, 39(10):1585-1596.

61. Arnold IC, Dehzad N, Reuter S, Martin H, Becher B, Taube C, Muller A: Helicobacter pylori infection prevents allergic asthma in mouse models through the induction of regulatory T cells. J Clin Investig 2011, 121(8):3088-3093.

62. Donaldson DS, Apostolaki M, Bone HK, Richards CM, Williams NA: The Escherichia coli heat-labile enterotoxin $B$ subunit protects from allergic airway disease development by inducing CD4+ regulatory T cells. Mucosal Immunol 2013, 6(3):535-546.

63. Macaubas $C$, Dekruyff $\mathrm{RH}$, Umetsu DT: Respiratory tolerance in the protection against asthma. Curr Drug Targets Inflamm Allergy 2003 2(2):175-186.

64. Frati F, Moingeon P, Marcucci F, Puccinelli P, Sensi L, Di Cara G, Incorvaia C: Mucosal immunization application to allergic disease: sublingual immunotherapy. Allergy Asthma Proc 2007, 28(1):35-39.
65. Jutel M, Akdis CA: T-cell regulatory mechanisms in specific immunotherapy. Chem Immunol Allergy 2008, 94:158-177.

66. Tsai YG, Chiou YL, Chien JW, Wu HP, Lin CY: Induction of IL-10+ CD4+ CD25+ regulatory $T$ cells with decreased NF-kappaB expression during immunotherapy. Pediatric Allergy and Immunology: official publication of the European Society of Pediatric Allergy and Immunology 2010, 21(1 Pt 2):e166-173.

67. Maizels RM: Infections and allergy - helminths, hygiene and host immune regulation. Curr Opin Immunol 2005, 17(6):656-661

68. Wilson MS, Maizels RM: Regulatory T cells induced by parasites and the modulation of allergic responses. Chem Immunol Allergy 2006, 90:176-195.

69. Smits HH, Engering A, van der Kleij D, de Jong EC, Schipper K, van Capel TM, Zaat BA, Yazdanbakhsh M, Wierenga EA, van Kooyk Y, Kapsenberg ML: Selective probiotic bacteria induce IL-10-producing regulatory $T$ cells in vitro by modulating dendritic cell function through dendritic cell-specific intercellular adhesion molecule 3-grabbing nonintegrin. J Allergy Clin Immunol 2005, 115(6):1260-1267.

70. Kearley J, Barker JE, Robinson DS, Lloyd CM: Resolution of airway inflammation and hyperreactivity after in vivo transfer of CD4 $+C D 25+$ regulatory $T$ cells is interleukin 10 dependent. J Exp Med 2005, 202(11):1539-1547.

71. Rindsjo $E$, Joerink $M$, Johansson C, Bremme K, Malmstrom V, Scheynius A Maternal allergic disease does not affect the phenotype of $T$ and $B$ cells or the immune response to allergens in neonates. Allergy 2010, 65(7):822-830

72. Wegienka G, Havstad S, Zoratti EM, Woodcroft KJ, Bobbitt KR, Ownby DR, Johnson CC: Regulatory T cells in prenatal blood samples: variability with pet exposure and sensitization. J Reprod Immunol 2009, 81(1):74-81.

doi:10.1186/1479-5876-12-125

Cite this article as: Zhang et al:: Subsets of regulatory $T$ cells and their roles in allergy. Journal of Translational Medicine 2014 12:125.

\section{Submit your next manuscript to BioMed Central and take full advantage of:}

- Convenient online submission

- Thorough peer review

- No space constraints or color figure charges

- Immediate publication on acceptance

- Inclusion in PubMed, CAS, Scopus and Google Scholar

- Research which is freely available for redistribution 